\title{
Technology-aided participative methods in environmental assessment: An international perspective
}

Ainhoa Gonzalez

Alan Gilmer

Technological University of Dublin, alan.gilmer@tudublin.ie

RanowntFileakd additional works at: https://arrow.tudublin.ie/beschspart

Notional University of Ireland

Part of the Business and Corporate Communications Commons, Communication Technology and New Media Commons, Digital Communications and Networking Commons, Educational Assessment,

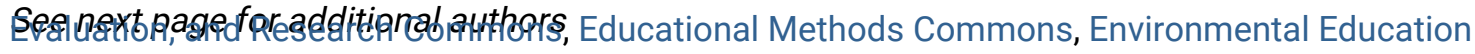
Commons, Environmental Health and Protection Commons, Environmental Indicators and Impact Assessment Commons, Environmental Monitoring Commons, International and Intercultural Communication Commons, Interpersonal and Small Group Communication Commons, Management Sciences and Quantitative Methods Commons, Natural Resource Economics Commons, Natural Resources and Conservation Commons, Natural Resources Management and Policy Commons, Other Business Commons, Public Affairs, Public Policy and Public Administration Commons, and the Sustainability Commons

\section{Recommended Citation}

Gonzalez, A., Gilmer, A., \& Foley, R. (2008). Technology-aided participative methods in environmental assessment: An international perspective. Computers, Environment and Urban Systems vol. 32 pg. 303-316. doi:10.1016/j.compenvurbsys.2008.02.001

This Article is brought to you for free and open access by the School of Transport Engineering, Environment and Planning at ARROW@TU Dublin. It has been accepted for inclusion in Articles by an authorized administrator of ARROW@TU Dublin. For more information, please contact arrow.admin@tudublin.ie, aisling.coyne@tudublin.ie,gerard.connolly@tudublin.ie.

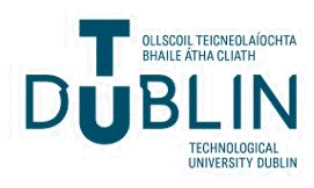


Authors

Ainhoa Gonzalez, Alan Gilmer, Ronan Foley, John Sweeney, and John Fry

This article is available at ARROW@TU Dublin: https://arrow.tudublin.ie/beschspart/10 


\title{
Technology-aided participative methods in environmental assessment: An international perspective
}

\author{
Ainhoa González $^{\mathrm{a}, *}$, Alan Gilmer ${ }^{\mathrm{a}, 1}$, Ronan Foley ${ }^{\mathrm{b}, 2}$, John Sweeney ${ }^{\mathrm{c}, 3}$, John Fry ${ }^{\mathrm{d}, 4}$ \\ ${ }^{a}$ Department of Environment \& Planning, Dublin Institute of Technology, Zhivago Building, Bolton Street, Dublin 1, Ireland \\ ${ }^{\mathrm{b}}$ National Centre for Geo-computation, National University of Ireland, Maynooth, Co. Kildare, Ireland \\ ${ }^{\mathrm{c}}$ Department of Geography, National University of Ireland, Maynooth, Co. Kildare, Ireland \\ ${ }^{\mathrm{d}}$ School of Biology and Environmental Science, UCD Dublin, Belfield, Dublin 4, Ireland
}

Received 6 March 2007; received in revised form 9 December 2007; accepted 10 February 2008

\begin{abstract}
Provisions for citizen involvement in the assessment of potential environmental effects of certain plans, programmes and projects are present in current legislation. An international survey revealed that public participation is common practice in European and some other countries worldwide. However, a number of issues are observed to affect public involvement in EIA/SEA processes and expert opinion differs when evaluating the effectiveness of existing participative methods.

Results suggest that technology-aided methods can improve traditional participation processes. In particular, GIS has the potential to increase community knowledge and enhance involvement by communicating information more effectively. Variable accessibility to technology and data quality remain issues. Combining technology with more conventional ways of gathering, evaluating and presenting data are seen as offering a solution to the need to promote the integration of public perceptions in environmental assessment procedures. Recommendations to improve current public participation methods and measures for making GIS available to the general public are provided.
\end{abstract}

(C) 2008 Elsevier Ltd. All rights reserved.

Keywords: Public participation; Effectiveness; Methods; Technology; Geographic information system

\section{Introduction}

The importance of public involvement in environmental decision-making has been well recognised (UNECE, 1998). Public participation exemplifies an opportunity to manifest the public right to democracy (Arnstein, 1969; Creighton, 2005; Pring, Zillman, \& Lucas, 2003). Information technologies (IT) and geographic information systems (GIS) are

\footnotetext{
* Corresponding author. Tel.: +353 876624879 .

E-mail addresses: ainhoag@yahoo.com (A. González), alan.gilmer@ dit.ie (A. Gilmer), ronan.foley@nuim.ie (R. Foley), john.sweeney@ nuim.ie (J. Sweeney), john.fry@ucd.ie (J. Fry).

${ }^{1}$ Tel.: +35314023806

2 Tel.: +3537086024 .

${ }^{3}$ Tel.: +3537083684.

${ }^{4}$ Tel.: +353716 7730 .
}

among the technologies used to assist public involvement in environmental assessment. The effectiveness of participative processes has been widely discussed in the literature (Abelson, Forest, Smith, Martin, \& Gauvin, 2001; Arnstein, 1969; Bishop, 1998; Connor, 1999; Creighton, 1992; Elwood \& Leitner, 1998; Portney, 1991; Speller \& Ravenscroft, 2005). Similarly, a number of studies have explored the potential of GIS-based participatory processes in land use planning and environmental assessment (e.g. Al-Kodmany, 2002; Bojórquez-Tapia, Diaz-Mondragón, \& Ezcurra, 2001; Hopkins, Twidale, \& Pallathucheril, 2004; Howard, 1998; Jordan \& Shrestha, 2000; Kingston, 1998; Kingston, Carver, Evans, \& Turton 2000; Wood, 2005). Notwithstanding the considerable examination of public participation effectiveness and IT/GIS-based participation, there has been little exploration of the opinions experts 
may have about current practice. Individual case studies identify locally-specific determinants of public participation but fail to provide a wider view on what is being done in the international public participation arena. This paper offers some insights into international expert perceptions to public participation practice and emerging IT- and GIS-based approaches with regard to public involvement in environmental planning.

Although various definitions of public participation exist, all encompass three distinct but mutually interconnected categories of public rights: (1) the right of "access to information", (2) the right of "participation in decision-making", and (3) the right of "access to justice" (Pring et al., 2003). Public participation in environmental assessment can be defined as the process by which proposed developments and plans are subject to public review and comment in order to improve the integration of socio-economic and environmental concerns. In essence, public participation is the process by which public concerns, needs, and values are incorporated into decision-making (Creighton, 2005). Therefore, an effective process should involve citizens in decisions about and the implications of social and economic change (Carver, 2003). Thus, it is argued that the legitimacy of the process will be enhanced (Susskind \& Cruikshank, 1987) and planning quality improved through participative decision-making. Furthermore, citizen inputs are recognised as an important source of expertise (Liebow, 1993), and public involvement provides a way to exchange information on local conditions and values (Creighton, 1992). It is a two-way communication and interaction, with the overall goal of more sustainable decisions that are supported by the public (Connor, 1999; Creighton, 2005).

In Europe, these principles are supported by the Environmental Impact Assessment (EIA) Directive (CEC, 1985, 1997), the Strategic Environmental Assessment (SEA) Directive (CEC, 2001), the Århus Convention (UNECE, 1998) and the related Directive 2003/35/EC (CEC, 2003), all of which emphasise and make mandatory provisions for public participation in the assessment of the potential effects of certain projects, plans and programmes on the environment. The EIA Directive established the requirements for the assessment of the potential environmental effects of developing individual [public or private, small- or large-scale] projects such as roads, housing states or power stations. In contrast, the SEA Directive refers to the assessment of plans (e.g. land use development) and programmes (e.g. waste management); thereby, covering broader environmental effects at higher planning levels. Internationally, various countries have established legal instruments to embed the need for public participation in environmental assessment such as the National Environmental Protection Policy Act in the USA (NEPA, 1969), the EIA Ordinance in Hong Kong (EPD, 1997) and the Cabinet Order in Canada (CEAA, 1999, 2004). Environmental assessment and planning processes generally have a public participation component; particularly in large- scale projects and high-tier planning (e.g. county development plans).

Despite the availability of legal instruments in planning and decision-making systems, effectively empowering public rights to information and greater democracy in decisionmaking remain the focus of continuous debate. The issue of public participation in Europe has been of particular relevance since the implementation of the amended EIA Directive (CEC, 1997). This has been re-emphasized by the mandatory integration of public opinion in strategic environmental decision-making as a result of the recently implemented Directive 2003/35/EC (CEC, 2003).

Analysis of the literature on public participation methods used in environmental assessment (e.g. Cinderby, 1999; Jordan \& Shrestha, 2000; Schroeder, 1997; Siebenhüner \& Barth, 2004; Stolp, Groen, Van Vliet, \& Vanclay, 2004) revealed a distinct trend of thought among experts and practitioners. Consultation is commonly undertaken at some stage in the process and is viewed as an essential ingredient of democracy (Creighton, 2005). However, current participative processes generally fall short of achieving their objectives in this regard (Carver, 2001; Scott \& Oelofse, 2005; Siebenhüner \& Barth, 2004; Towers, 1997). Connor (1999) highlights that most participatory methods rely on communicative approaches (e.g. oral hearings) and interactive processes (e.g. workshops). These methods could generally be classified within the lower rungs of Arnstein (1969) or Kingston (1998) ladder analogies as presenting non-participatory processes to "educate" or symbolic processes to inform and consult the public, where real negotiation and partnership are absent (Fig. 1). In both analogies, consecutively higher rungs indicate increased levels of involvement and greater public empowerment in decision-making. However, these higher rungs are seldom reached in conventional public participation. The provision of fully representative stakeholder involvement, accountability, and timely concern and interest incorporation have

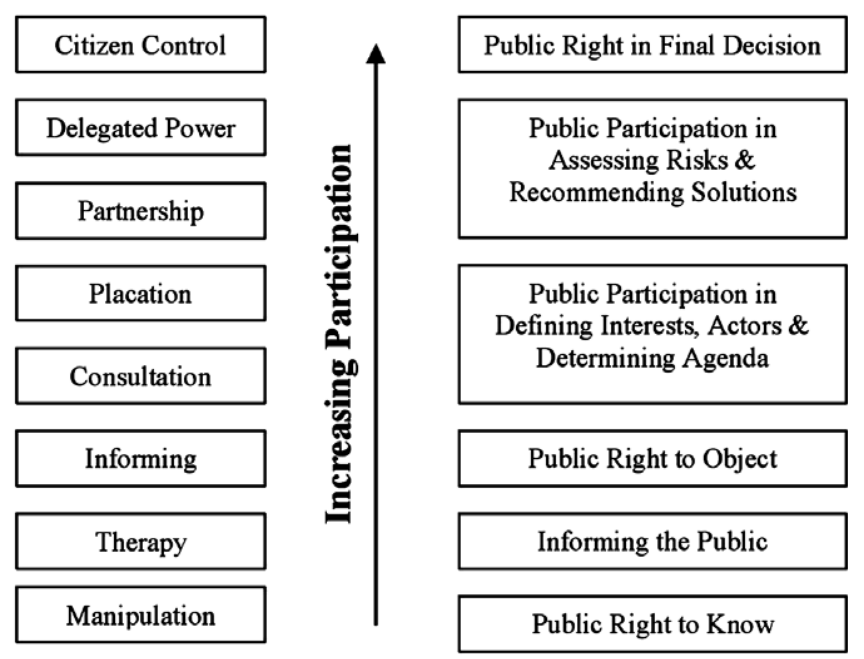

Fig. 1. Comparison of Arnstein (1969) [left] and Kingston (1998) [right] ladder analogies for public participation. 
rarely been effective in such settings (Morris \& Morris, 2005; Shepherd \& Bowler, 1997).

Participative methodologies are based on the premise that stakeholders have democratic right to identify and shape their lives through access to knowledge, political processes and financial, social and natural resources (Arnstein, 1969). In this context, the general public should have the opportunity to participate in decision-making. However, the public is often segmented into interest groups, geographic communities and individuals (Bishop, 1998). In consequence, participatory processes should accommodate individual citizens or representatives of groups of people sharing a common view. Nevertheless, practice suggests that willingness to become actively involved is lacking across populations as a whole (Carver, 2001); possibly as a result of poor community involvement, deficient participative frameworks/methods, lack of interest, time and/or resources or mistrust in decision-making systems. Moreover, participative methods often fail to combine different approaches to target different interest groups. Instead, public displays, hearings and workshops (which provide a higher degree of two-way communication - Abelson et al., 2001; Bishop, 1973) generally address all interested parties at once. Such meetings tend to be unevenly dominated by a minority of vocal representatives (Carver, 2003; Rugg, 2003) whose views may not necessarily represent the wider opinion of local people (Carver, 2001; Kingston, 1998). Individuals and community groups tend to become engaged only when the issue directly affects them (NIMBY ${ }^{5}$ or LULU $^{6}$ effects). Therefore, the effects of space, place, locality and proximity are identified as key factors in determining public interest in decision-making problems (Carver, 2003). An additional potential contributing factor to increasing public interest may also include media promotion and interpretation of particular issues. As a consequence, the outcomes of public consultation tend to reflect the disapproving views of concerned individuals/groups. Although the representativeness and the validity of the outcomes can be questioned in both direct and mediated (i.e. via representatives) participation (Allen, 1998), active involvement and incorporation of public interests still represent a step towards democratic decision-making, particularly in environmental settings.

There is also an additional temporal dimension to participation. As planning progresses, some of the initially identified stakeholders (whether individuals or groups) do not participate, while previously unidentified individuals/ groups may attempt to get involved (Bishop, 1998). Public meetings carried out at a certain time in a certain place provide no scope for participation outside set time frames. As a result, interest in new forms of technology-aided public participation has developed in the last decade. Such new forms of participation arguably allow respondents to make

\footnotetext{
${ }^{5}$ Not in my back yard.

${ }^{6}$ Locally unwanted land use.
}

comments and express views in a relatively anonymous way anytime from any location (Carver, 2001).

The increasing use of IT and GIS has the potential to bring significant innovation to traditional participative methods. However, using the Internet as a mechanism to provide information to reach a wider public and to assist in the participative processes is equally the subject of concern. While one school of thought advocates that Internetbased technologies can enhance wider participation levels (Carver, 2001; Doyle, Dodge, \& Smith, 1998; Kavanaugha, Carrollb, Rossonb, Reesec, \& Zina, 2005), it is also argued that access to the Internet and associated technology is limited (Kangas \& Store, 2003; Kingston, 1998), which consequently limits the scope for participation. In addition, issues such as the division between the computer-skilled (e-literate) and citizens with no computer knowledge (non-e-literate) - also known as the 'digital divide' (Oden \& Lentz, 2001) - and the relative levels of social inclusiveness need to be addressed (Furlong, 2005; Kingston, 1998; Loveridge \& Street, 2005; Scott \& Oelofse, 2005).

The rapid development of IT in decision-making has begun to consider GIS to enhance understanding of issues through the visual depiction of relevant information. In using GIS, it may be considered that spatial representation can enhance understanding (Cinderby, 1999) and, thus, can be used to support and supplement existing participatory channels. However, it is necessary to bear in mind the limitations imposed by social structures and institutional arrangements; de Man (2003) notes that approaches which use IT are likely to have limited effects in societies that are not supportive to participation in general. Notwithstanding these limitations, public participation methods that combine IT approaches (such as GIS-aided workshops and Internet-based consultations) with a more interpersonal dimension (such as seminars, events, workshops, exhibitions, etc.) may still represent a favourable alternative to both inform and involve e-literate and non-e-literate citizens. The application of GIS- and Internet-based technologies implies an additional set of challenges, including:

- Accessibility to the tools (Carver, 2003) and data (Craglia \& Masser, 2003; de Man, 2003; Niles \& Hanson, 2003).

- Divergences observed among citizens' visual/spatial literacy and the associated understanding and interpretation of spatial information (Al-Kodmany, 2002; Craglia \& Onsrud, 2003; Jankowski \& Nyerges 2003).

- Representativeness of the data generated and validation of individual responses (Carver, 2003); and

- Effective incorporation of non-expert knowledge into the final decision.

As a result of all these considerations, this paper sought to explore in more detail these perceptions and challenges, to analyse the tensions (i.e. opportunities and barriers) underlying the differing viewpoints and to suggest some practical recommendations to improve public involvement 
in environmental decision-making, as well as to promote IT/GIS as participative tools.

\section{Methodology: survey parameters}

A questionnaire was prepared to gather the views of international EIA and SEA practitioners in relation to public participation performance. The survey sought to gather opinions from expert professionals for the following reasons: the need to obtain a breath of views to see whether some sort of international consensus was possible; accepting varying understanding and definitions of public participation, to observe whether there was a commonality of opinion on the factors that might impact on the use of IT/GIS-based approaches; and, more broadly, to record experts' attitudes to emerging participative IT and GIS applications. Three key aspects were explored with the survey: (1) the implementation and effectiveness of current public participation procedures; (2) the levels of use and application of IT during participative processes; and (3) assessing the potential of GIS as a tool for information sharing and collation. Consequently, the research results were structured against these core themes, with questions developed against each as follows:

(1) Survey questions that addressed public participation covered a number of aspects including: general implementation status; effectiveness of public involvement (i.e. the ability of public consultation to have an effect on decision-making); the potential deficiencies in EIA public participation to seep across into SEA; the necessity for developing comprehensive guidelines for public participation in SEA; the importance of consensus and consensus-led decision-making; and the relative impact of the participative processes on final decisions. Key principles affecting the efficacy of participatory methods were also reviewed.

(2) The perception that public participation entails significant time and resources was also explored. To address this, the study assessed feelings about whether IT was a feasible participatory tool to facilitate public involvement and engage all social/educational levels. In addition, questions addressed concerns over IT accessibility and means to make IT more fully available to the general public.

(3) The final set of questions focused on the potential of GIS as a public participation tool. The usefulness of GIS methods for public participation was investigated. The significance of early public input into the GIS methodology (to identify relevant data and spatial analysis criteria) was also examined, together with data issues related to ownership, quality and accessibility. To conclude, recommendations were sought from respondents on actions/measures to make GIS more effective as a participatory tool and to improve spatial data quality and accessibility.
The International Association for Impact Assessment (IAIA) is the world's leading collective authority on best practice in the use of impact assessment for informed decision-making. The survey targeted one hundred established members of IAIA including private consultants, planners, managers, public interest advocates, administrators, policy analysts, university teachers and researchers involved in SEA and EIA. This selection of individuals was based on the following criteria:

- The background research focused on European environmental assessment practice; therefore, all European countries represented at the first global SEA conference (2005) were targeted (Fig. 2). Two members from each country were selected from the participants list.

- Input from the wider international community was also appropriate considering the range of approaches, views and experience in the environmental and public participation arenas. Thus, at least one member from each non-European country represented at the conference was included in the survey (Fig. 2).

- Selection within countries targeted academics and authors who have contributed significantly to international literature and debate on public participation and EIA/SEA.

\section{Results: assessing worldwide public participation practice}

The study generated inputs from 54 respondents (i.e. $54 \%$ response rate) - representing 21 developed countries (13 European and eight non-European) and five developing countries (Fig. 2). The questionnaire provided insights into possible commonalities related to the wider group of EIA/ SEA practitioners/academics. It also provided data supporting the establishment of a general agreement regarding public participation practice and the interplay between the public and IT.

\subsection{Implementing public participation: an overview of expert opinion}

The majority $(81 \%)$ of the respondents identified their environmental assessment and planning processes as having a public participation component. Despite citizen involvement being common practice in most countries, opinions in relation to the effectiveness of implementation and practice diverged (Section 3.2). It was observed that public involvement in environmental decision-making is strongly dependant on relevant legal instruments and, despite the harmonisation provided by EU Directives, the nature of public involvement in decision-making differs significantly. Participative processes are well-established in those countries with strong planning and environmental systems (e.g. Austria, The Netherlands and the UK). However, even here the level of participation is highly variable 


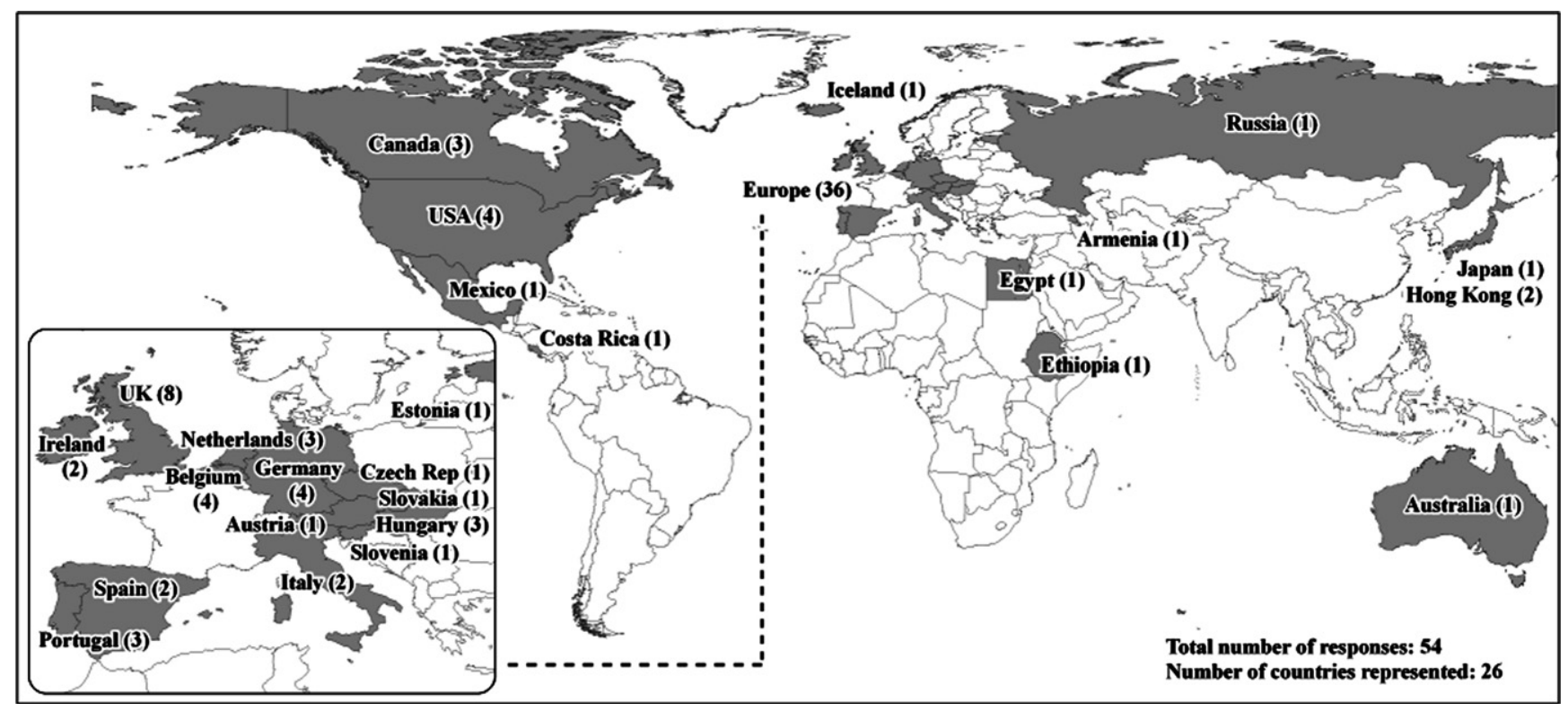

Fig. 2. Countries that contributed to the international survey and number of respondents per country.

and the most effective examples were perceived to occur in proactive non-statutory (i.e. informal) situations. Participation was unanimously viewed as an important awarenessraising activity. However, despite legal prerequisites, the study suggested that there is a general lack of culture for engaging the public adequately in most countries; in many cases participative processes do not go beyond consultation. Although consultation may be a legitimate step to involve the public in decision-making, it is predominantly a oneway communication process (i.e. information flows from the proponent/s to citizens) and falls halfway on both Arnstein (1969) and Kingston (1998) ladders (Fig. 1). It informs the public and provides them with the mechanism to object to or comment on proposals. However, the surveyed opinion suggested that negotiation and partnership are largely absent in most countries and the full decision-making responsibilities are reserved for power-holders.

\subsection{Effectiveness of current participative processes}

Considerable variation was observed between countries with regard to the effectiveness of current participative processes (Table 1). There was a broad division among experts: $37 \%$ considered public participation to be predominantly effective while $44 \%$ argued that efficient participation only occurred in a small number of cases. Responses from European and non-European developed countries broadly agreed in this point. However, responses from developing countries maintained that participation was commonly ineffective. Individual respondents in the UK noted that, despite well-established participative methods, lack of information and appropriate induction were still issues working against effective participation. It was also noted that efforts at promoting public engagement in the UK continue to adopt a minimalist approach. In Ireland, public consultation occurs but it was inconsistent and largely

Table 1

Effectiveness of public participation processes in EIA/SEA according to responses per country

\begin{tabular}{|c|c|c|c|c|}
\hline \multirow[t]{2}{*}{ Country } & \multirow[t]{2}{*}{ No. of respondents } & \multicolumn{3}{|c|}{ Effectiveness of public participation } \\
\hline & & Effective & $\begin{array}{l}\text { Sometimes } \\
\text { effective }\end{array}$ & $\begin{array}{l}\text { Non- } \\
\text { effective }\end{array}$ \\
\hline EU & 36 & $12(33 \%)$ & $17(47 \%)$ & $7(20 \%)$ \\
\hline Austria & 1 & & レ & \\
\hline Belgium & 4 & レレ & $\boldsymbol{\nu}$ & $\boldsymbol{V}$ \\
\hline Czech Rep. & 1 & $\nu$ & & \\
\hline Estonia & 1 & & $\boldsymbol{\nu}$ & \\
\hline Germany & 4 & & レレレ & $\boldsymbol{v}$ \\
\hline Hungary & 3 & レレ & レ & \\
\hline Ireland & 2 & $\boldsymbol{}$ & レ & \\
\hline Italy & 2 & レ & $\nu$ & \\
\hline Netherlands & 3 & レル & レ & \\
\hline Portugal & 3 & レ & レル & \\
\hline Slovakia & 1 & レ & & \\
\hline Slovenia & 1 & & & $\boldsymbol{r}$ \\
\hline Spain & 2 & & レ & $\boldsymbol{\nu}$ \\
\hline UK & 8 & レ & レレレレ & レレ \\
\hline Non-EU & 18 & $8(44 \%)$ & $7(39 \%)$ & $3(17 \%)$ \\
\hline Armenia & 1 & $\nu$ & & \\
\hline Australia & 1 & レ & & \\
\hline Canada & 3 & レ & & $v$ \\
\hline Costa Rica & 1 & 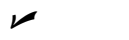 & & \\
\hline Egypt & 1 & & $\nu$ & \\
\hline Ethiopia & 1 & & & $v$ \\
\hline Hong Kong & 2 & $\nu$ & $\nu$ & \\
\hline Iceland & 1 & & $\nu$ & \\
\hline Japan & 1 & & レ & \\
\hline Mexico & 1 & & & $\nu$ \\
\hline Russia & 1 & $\nu$ & & \\
\hline USA & 4 & $\nu$ & レレ & \\
\hline Total & 54 & $20(37 \%)$ & $24(44 \%)$ & $10(19 \%)$ \\
\hline
\end{tabular}


driven by the need to comply with legal mandates in largescale projects. In Spain, public participation was considered to be an opportunity taken by interest groups to achieve non-environmental objectives (e.g. economic gains). Australian participative processes were considered to be operational: the public are consulted during environmental assessment procedures and the proponent is required to respond to the comments prior to decisionmaking. In Japan a passive approach to full public participation was generally the case, where silence or nonparticipation is regarded as acquiescence. In Ethiopia, lack of inclusion of public concerns in EIS report was indicated as being common practice. In most of the countries surveyed, public participation as part of EIA/SEA was not considered to have been effectively implemented, even where there is a relevant legislative context (Table 1). The survey evidence suggested that the agenda is generally set and dominated by power-holders.

Most respondents (92\%) considered community consultation and involvement a valuable input to decision-making - i.e. citizens' views and knowledge could provide additional and constructive information previously unknown to the assessment process, and the incorporation of such concerns and interests contribute to improved democracy. Nevertheless, a smaller majority $(62 \%)$ suggested that existing participatory procedures do not fully achieve the intended effect, as public involvement is limited and results are not properly integrated into decision-making. Current practice was perceived as being selective, limited to legal requirements and not fully effective. Individual responses noted that the accountability and validity of results are case-specific and depend on the scale of the proposal, level of engagement, existence of vested interests, methods applied and the experience of the professionals undertaking it.

A number of factors were reported to influence the effectiveness of public involvement. At the international level, it was generally perceived $(62 \%)$ that lack of clear guidance has led to poor performance in public participation in EIA. This often manifested itself in late and inadequate engagement with the public or a lack of recognition of public concerns and interest. It was considered that such previous negative experiences and a general unwillingness to effectively involve the public have the potential to affect the implementation of participative processes for SEA. Therefore, most experts and practitioners agreed that there is a need to develop clearer public participation guidance documents in SEA, particularly in relation to stakeholder identification and the application of appropriate participative tools/methods. Guidance documents for the two-way provision of participative processes are only available in countries with strong planning and environmental systems (e.g. The Netherlands and the UK). However, regardless of public involvement guidelines, the results indicated that the main factor affecting community involvement is a lack of political will derived from a failure to understand the benefits of public participation. This in turn may be associ- ated with either a lack of trust in citizens (Yang, 2005) or other barriers to community empowerment such as political arrangements and bureaucracy (Kyem, 2002). The study results also confirmed that lack of public awareness or ignorance of EIA and SEA processes, and their potential for influencing final decisions could also hinder participation.

\subsection{Consensus: benefit or quandary?}

This study suggested that consensus is not necessarily perceived as the goal of public participation. In current practice, public participation outcomes were noted as being restricted to informing decision-making. Consequently, current participative processes tend to focus on informing citizens and raising public support rather than on consensus-seeking approaches. In effect, although a closer agreement on objectives may be attained, consensus is very rare as not all individuals or groups will be satisfied with the end result.

Results were internally divided when assessing the sustainability of consensus-led public decision-making; particularly as it was often seen that sustainability criteria were dependant on the specific location, values and development context. A number of respondents (36\% European and 62\% non-European) stated that reaching consensus in EIA/SEA generally renders better outcomes, improves proposal's sustainability and results in wider public acceptance. Fuller information, engagement, ownership and established tradeoffs are likely to lead to more sustainable planning trends. Susskind (1999) suggests that consensus will be reached when it is agreed that every effort has been made to meet the interests of all stakeholders. The benefit of the consensus-approach is based in the fact that if there is legitimate agreement, the proponent can proceed with reasonable confidence that implementation is supported. In contrast, it was argued by four practitioners in Europe that the majority of people tend to focus on short-term benefits and therefore non-sustainable outcomes are likely when consensus is attained. This relates to the observation made by Peterson, Peterson, and Tarla (2005), supported by Helge (2005), who argue that consensus-based approaches could have dangerous implications, as reconciling the potentially incompatible goals of environmental protection and economic growth could legitimise unsustainable social constructions of reality.

Sustainability of outcomes depends on many aspects, and public participation represents an important one of these. However, there was agreement among respondents that despite the public consensus quandary, citizen empowerment or input to the final decision is uncommon; and outcomes, sustainable or otherwise, are largely determined by power-holders. This study indicated that in the majority of cases development takes place unmodified by public participation. An individual respondent considered that in our fragmented and complex societies the public rarely has enough power to impede or enable developments through formal public participation procedures. 


\subsection{Improving the effectiveness of public participation methods}

A question on effectiveness revealed that the performance of existing participatory methods is generally poor. Yet it was recognised by nearly all respondents $(98 \%)$ that participative processes have the potential to improve informed decisions (i.e. integrating local knowledge), lend credibility to the proposal, and overcome conflict (i.e. gaining public support). In particular, the following issues were identified by respondents as potentially enhancing empowerment:

- Provision of information in a transparent manner.

- Promoting a two-way communication.

- Raising awareness (combined with education, enhanced knowledge and explanation of benefits to society).

- Building trust, collaborative capacity and understanding between stakeholders.

- Demonstrating an openness and willingness to engage the public (i.e. viewing public participation as a positive component in decision-making not as a constraint).

- Providing community members with a voice, allowing them to participate in a meaningful way and creating opportunities for involvement.

- Showing an interest in people and generating shared responsibilities (i.e. co-responsibility).

- Ensuring inclusivity and representation of minority groups.

- Bringing conflict into light and addressing it; and

- Showing evidence that the results of public participation are taken into consideration.

There was broad agreement (64\%) that public participation methods following a case-by-case approach are better at adapting to specific needs. However, such an approach is not always a feasible or affordable option. There was general support for the development of a standard procedure (either by developing guidelines or by establishing it in the terms of reference), that could then be adapted to the specific communication/information needs of the affected/ concerned public. General procedures vary widely from country to country. This could be related to the fact that there is little guidance on how to identify, establish and support individual groups to ensure adequate engagement in decision-making processes (Speller \& Ravenscroft, 2005). A replicable and systematic approach would give credibility and consistency to the process, while controlled case-by-case variation or adaptation would complement it.

\section{Results: IT and public participation}

As a result of the social, spatial and temporal dimension of participative processes, there is a growing need to effectively communicate with local and global, expert and nonexpert audiences alike. Distribution of information through emerging technologies, such as the Internet, is gaining popularity as a rapid and useful way of informing and involving the public. IT is advocated as a key tool to facilitate and widen participation, and is widely viewed as a feasible option to engage the public (Carver, 2001; Cinderby, 1999; Hopkins et al., 2004; Kingston et al., 2000; Weiner, Harris, \& Craig, 2002).

\subsection{The potential role of IT in participative processes}

The results of this study (Table 2) indicated that, despite IT being a suitable participation tool, it could not reach all people (e.g. young, elderly, illiterate, lower social classes, etc.). It was generally perceived $(58 \%)$ that the potential to provide and gather information through IT is affected by issues such as accessibility to the Internet and associated software technology among other things. The respondents from developing countries indicated that this is exacerbated where IT accessibility is limited and does not reach rural areas, minorities and lower social groups. These issues of accessibility have been extensively documented (Bauer, Berne, \& Maitland, 2002; Niles \& Hanson, 2003; Oden \& Lentz, 2001; Simpson, Daws, \& Pini, 2004) as have the opportunities, limitations and challenges encountered when using computer technology (Charlton, Gittings, Leng, Little, \& Neilson, 1999; Curwell et al., 2005; Merrick, 2003; Shiffer, 1995). Accessibility issues are of particular relevance in developing countries (Brooks, Donovan, \& Rumble, 2005). A few respondents (9\%) argued that its use is rather selective and that its application is limited even for e-skilled citizens with full-time technology access. Observed weaknesses included information overload, the relevance of the information, capacity to interpret data (cf. Niles \& Hanson, 2003) and the opportunity and time to engage people in dialogue.

Notwithstanding the reported problems and concerns regarding the use of IT infrastructure, $55 \%$ of respondents considered IT tools to represent a significant opportunity to enhance public participation in environmental assessment and planning processes. However, it was also recognised that such IT tools could not fully replace other communicational forms of consultation. Despite the current European trend of increasing reliance on IT for both information delivery (e.g. e-tax) and decision-making (e.g. e-voting), the potential role of information technologies for public participation remains unclear (Roche, 2003). A majority of respondents $(70 \%)$ suggested combining IT tools with other instruments, such as hearings, workshops and public displays. This was seen as offering a solution to the need to simultaneously enhance participative processes and facilitate integration of public perceptions into the assessment. It was stated by some respondents $(18 \%)$ that a physical presence and a willingness to talk one-toone, openness to communication and visibly recording consultees' views are important aspects of a participation process. On the other hand, $11 \%$ of consulted experts observed that contemporary forms of e-participation provide an opportunity to enhance involvement as they have the potential to break down the spatial and temporal, commu- 
Table 2

IT \& GIS accessibility and the contribution of GIS to public participation according to responses per country

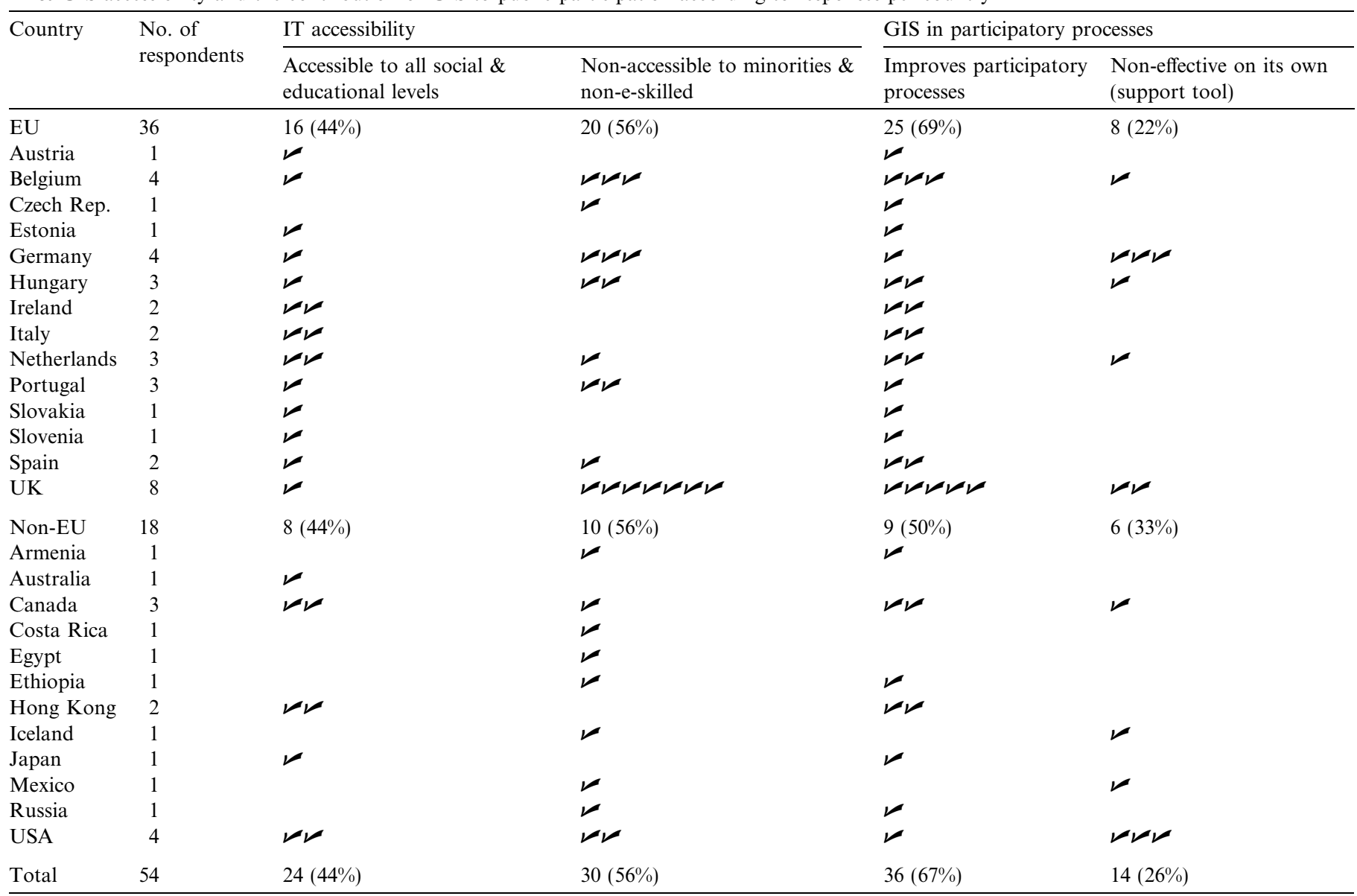

nicative, social and gender barriers inherent in 'traditional' public participation structures. However, several concerns were also noted in relation to IT-aided participation. These derive from the apparent 'digital divide' (Brooks et al., 2005; Oden \& Lentz, 2001), and the varying degrees of success with regards to initiatives around social inclusiveness (Furlong, 2005; Loveridge \& Street, 2005; Scott \& Oelofse, 2005). An individual respondent observed that IT could have an effect with the appropriate allocation of resources and linkage to policies that raise educational capacities and opportunities. It can be concluded that IT tools could be used to support and supplement 'traditional' participatory methods for widening public consultation but that significant obstacles remain. Multiple approaches and the provision of tools adapted to audience needs could be a way to enhance participatory processes and improve citizen input into the final decision.

\subsection{Improving IT accessibility}

People are becoming more familiar with technology and the gap between e-literate and non-e-literate is decreasing to the extent that the next generation will probably constitute a critical mass demanding IT-aided information and interaction (Weiner et al., 2002). However, 54\% of respon- dents considered that the gap can only be bridged in the short-term with significant efforts to promote greater development of IT skills within society. Key steps suggested to promote understanding and use of IT include:

- Education and training. This is a slow but necessary process to achieve enhanced technological knowledge. In the short-term, open communication and the use of e-tools in planning can proactively promote interest and involvement.

- Extending availability of IT. Improving access to technology by making computers and Internet services more widely available (both in society and within the home).

- Internet accessibility. Enhancing design of user-friendly, culturally-sensitive interfaces with appropriate information focus can increase Internet use by the general public.

\section{Results: GIS in public participation}

There has been an increasing interest in public GIS use in recent years (e.g. Al-Kodmany, 2002; Elwood \& Leitner, 1998; Goodchild, Egenhofer, Kemp, Mark, \& Sheppard, 1999; Kingston, 1998; Kingston et al. 2000) and Public Participation GIS (PPGIS) has developed as a research field 
that focuses on the development of user-friendly GIS interfaces (Haklay \& Tobón, 2003). However, there is still a significant gap between experimental and practical application of participatory GIS and very few real-life case studies have been published (e.g. Jordan \& Shrestha, 2000; Kingston et al., 2000; Weiner \& Harris, 2003). Despite its potential as a communicative medium, public access to data, software and expertise remain issues.

\subsection{The potential of GIS as a tool for public participation}

Although it has been argued that participatory GIS cannot be effective on its own due to limited access to the technology and the apparent complexity of the system (Al-Kodmany, 2002; Kangas \& Store, 2003; Kingston, 1998; Oden \& Lentz, 2001), this study found strong support $(70 \%)$ for the use of GIS to assist public involvement processes (Table 2). It was felt that it could help people to spatially visualise and understand where problems are located. It could also provide a visual link, communicating information more effectively and illustrating potential outcomes of possible future scenarios. Furthermore, it was recognised that GIS could provide significant advantages in public participation based on their potential to correlate evidence and enhance opportunities to:

- Identify spatial aspects that had not been considered.

- Clearly and effectively communicate potential problems and results through spatial analysis.

- Improve understanding of the effects of alternatives (options/scenarios) by visualising them.

- Involve the public.

- Modify perceptions of a problem.

However, several respondents $(30 \%)$ alleged that the perceived potential of GIS as a participatory tool is currently limited by a number of factors, including the complexity of the GIS interface and access to appropriate (hardware and software) resources. These limiting factors have been widely examined and defined as key barriers to GIS use (Kangas \& Store, 2003; Kingston, 1998). Exclusion from the decision loop due to a lack of spatial literacy and understanding of maps (Al-Kodmany, 2002) and/or as a result of the 'digital divide' (Oden \& Lentz, 2001) are examples of these. Respondents also noted that perception is not solely geographic and that not everything translates easily into geographic form (e.g. feelings and value judgements). Moreover, a number of responses highlighted that GIS could be sensitive to misuse, misinterpretation and manipulation. GIS always represents reality in a simplified manner, which, in most cases, is influenced by the proponent. However, the receptor to that information may have a different understanding of what 'reality' is or what is environmentally important to them. Set against this, most data users in environmental planning lack local knowledge and community perspectives. In this context, participatory processes that are assisted by a facilitator could allow the incorporation of mapable local values and perceptions. Carver (2003) suggests that despite its limitations, the map still is the best way of organising spatial information and is the best available tool for interacting with it. A combination of expert and public opinion data may allow for investigation of multiple realities of a single issue, enhancing the shared understanding and knowledge for a particular site or resource and providing a more comprehensive picture of 'reality'. However, considering the limitations faced by many potential GIS users and the implications of applying GIS, it can be argued that GIS can only be applied as a complementary tool to support other means of gathering and presenting data during participative processes.

\subsection{Data implications in participative GIS}

GIS applications have experienced a significant expansion over the past decade. However, GIS expertise, and data accessibility, quality and interpretation remain issues worldwide. Despite widespread legislation on freedom of information, international evidence continued to identify limited public access to information. Data accessibility generally depends on the project and on the willingness of organisations and relevant administrative bodies to share information. Without the institutional readiness or appropriate measures that facilitate data sharing initiatives, restricted access to data cannot be overcome (de Montalvo, 2003). In addition, significant concerns exist in relation to data quality and corresponding elements such as accuracy, validity and manipulation. Lack of accuracy not only affects the final decisions, but also the credibility of agencies and organisations involved in the process. However, no general-purpose datasets could ever be constructed for all potential purposes, nor will data accuracy meet the demands of all uses (Onsrud, 1999). Absolute accuracy of data is not achievable; boundaries/limits need to be set at some point and some data will always be prone to uncertainty (e.g. geological boundaries can never be accurately mapped in GIS). Nevertheless, surveyed opinion suggested that accuracy can always be enhanced by quality control, validation and verification of field data. The risk that the interests of developers, assessors or decision-makers might influence the filtering of spatial information was also noted by the respondents. Consequently, it was observed that such manipulation might be limited by making original field data available to the public and ensuring transparency in the process. This is based on the premise that the more information is made publicly available, the less the risk of manipulation. The creation of an independent authority to check data quality, usability and processing was also perceived as a measure to help control potential manipulation and misuse of information. In addition, having the end-users involved from the beginning could give a better understanding of GIS aspects and methods, enhance process transparency and improve integration of local knowledge. A combination of public and expert knowledge 
would lead to a more comprehensive and balanced input to GIS and, therefore, a more acceptable outcome. In addition, it could help identify the needs and wishes of users and, consequently assist in potential modifications that could contribute to improving the acceptance and use of GIS within participatory processes.

Bearing in mind the potential 'threats' to data quality, the majority of respondents $(63 \%)$ stated that ensuring data are updated, complete and comprehensive could significantly contribute to their validity for an established purpose. In any case, uncertainty, gaps in knowledge and assumptions need to be acknowledged, as well as potential data variations resulting from changing environmental conditions and social values/perceptions. In addition, data processing or modelling methodologies need to be transparent if the outcomes are to be trusted and safely used. In this context, it was suggested that introducing standard procedures in GIS uncertainty management could help determine best data acquisition and management strategies.

The European Directive 2007/2/EC (CEC, 2007), also known as the INSPIRE ${ }^{7}$ Directive, aims to tackle some data issues by increasing the availability, accessibility, transparency and usability of spatial data - particularly environmental data. Further institutional efforts (such as the creation of Spatial Data Infrastructures at a variety of scales) are also required to ensure adequate data gathering, modelling and management. Respondents agreed that effective regulatory mechanisms such as these are needed to specify how data are collected and managed; and these in turn could be linked to the EIA/SEA regulations. Other measures suggested in the survey to improve data availability and accessibility include: increased political will to make data (particularly environmental data) freely available; research; investments in data gathering; resource allocation; monitoring of variables; training and field observations. Finally, measures identified as potentially increasing data validity include: a description of how information was obtained and processed (i.e. metadata); the identification of gaps in knowledge; the recognition of uncertainties; evidence of sensitivity analysis; and external independent expert reviews.

\subsection{Improving GIS usability in public participation}

Results suggested a number of measures to extend and improve GIS usability in public participation (Table 3), such as the creation of easy-to-use and easy-to-understand GIS solutions (without understating the complexity and interrelationships of environmental aspects) and the provision of education and training to end-users. Efforts are also required at administrative levels to make GIS tools fully available within the public participation arena. In addition, the study highlighted the need for more practical test appli-

\footnotetext{
${ }^{7}$ Infrastructure for spatial information in the European community.
}

Table 3

Measures specified by international EIA/SEA experts consulted to improve GIS usability in public participation

\begin{tabular}{ll}
\hline Measures to improve GIS usability in public participation & $\begin{array}{l}\text { No. of } \\
\text { respondents }\end{array}$ \\
\hline $\begin{array}{l}\text { Availability of internet-based GIS (both maps and } \\
\text { data) providing visual and interactive information. }\end{array}$ & $18 / 54(33 \%)$ \\
Enhance GIS knowledge and use through education \\
and information by planning and other public \\
authorities. GIS use during consultations and \\
community-based mapping exercises; involving the \\
public in the collection and analysis of data and \\
demonstrating how it is manipulated in GIS. \\
$\begin{array}{l}\text { Resolve licensing and information sharing issues: } \\
\text { improve data quality and reduce accessibility } \\
\text { limitations that restrict the ability of organisations to } \\
\text { make use of GIS. }\end{array}$ \\
$\begin{array}{l}\text { Provide human and financial resources to enable a } \\
\text { wider use of such systems; and reduce IT demands } \\
\text { (expensive software packages, data acquisition } \\
\text { problems, etc.). }\end{array}$ \\
$\begin{array}{l}\text { Make use of 3D technology to generate more realistic } \\
\text { images/models and enhance the use of palm- } \\
\text { computers that include GIS. }\end{array}$ \\
\hline
\end{tabular}

cations to increase experience and raise awareness about the potential of GIS-based participation.

Opinions expressed in this study indicated that providing Internet-based GIS improves public access to GIS in general and that this, in turn, leads to enhanced participative processes by conveying information in a more clear and visible form. However, Niles and Hanson (2003) also observe that physical access to infrastructure alone does not equate to equity of information accessibility. In addition, de Man (2003) suggests that access to geographic information, though necessary and enabling, is not a sufficient condition for participation in its use. This study revealed that attitudes diverge over traditional and innovative (i.e. including IT and/or GIS) methods of public participation, as well as over willingness to participate. Thus, it remains to be proven whether improving IT accessibility (e.g. providing computer resources and training) necessarily entails improving IT-based participation.

\section{Improving current practice}

The results of this study indicated that there still is considerable room for improvement in current public participation practice and the potential systematic application of IT and GIS to participative processes. Consideration should be given to the opportunities and barriers associated with public participation and PPGIS when designing community involvement methods and programmes. Collaboration between citizens, stakeholders, planners, consultants and decision-makers is essential for true participation (i.e. that which has influential and beneficial effect on the decision-making outcomes). Best practice recommendations for ensuring effective and legitimate public participation are summarised in Table 4. Although many of the 
Table 4

Recommendations by international EIA/SEA experts to improve current public participation processes

Recommendations to improve public participation No. of
respondents

$\checkmark$ Select participatory methods that are appropriate; adjust the scope of public participation to the scale of the proposal and direct the information to affected parties/ stakeholder groups. Use a combination of methods in e-based (e.g. Internet and GIS-based sites) and non-e-based (e.g. interviews, round-tables, public exhibitions, open forums, etc.) venues.

Provide simple ways of presenting the issues (e.g. use graphics, summarise difficult data, and use multiple methods to illustrate information).

Ensure that public participation starts early (from conception stage rather than solution stage), continues through the process and provides sufficient time so people can react and have a real input, to be able to make a difference to design/outcomes.

- Make it political and impose legal obligation on authorities to facilitate effective public engagement. Strengthen the public participation framework to recognise the democracy of results in the process.

$\checkmark$ Make sure that public participation is conducted by an independent and external consultancy. For each working group appoint a good unbiased chairperson/ facilitator (and, if necessary, an IT/GIS expert) who is able to clearly show the impacts of actions (and explain their spatial implications) to the public in workshop situation.

$\checkmark$ Ensure transparency of deliberations and decisionmaking by ensuring that all information and documentation (in both graphic and literal form) is easily accessible early in the process.

$\checkmark$ The process must be accountable - establish and explain values and trade-offs and explicit sustainability-based decision criteria; explain how public input was taken into account and, if not, why.

$\checkmark$ Design formal public participation guidelines or terms of reference for EIA/SEA, including systematic scoping guidelines to help identifying stakeholders and public participation methods and interactive tools required.

$\checkmark$ Encourage the public to get involved by sharing ownership - make civil society also assume responsibilities in finding solutions and make sure it is inclusive - find ways to reach minorities; indigenous people, etc.

$\checkmark$ Enhance trust among stakeholders and the general public and ensure dialogue and two-way communication (information and feedback) continuous communication during the planning process.

$\checkmark$ Follow up on SEA consultation - report publicly on consultant procedures and on how issues have been addressed.

$\checkmark$ Provide resources to train public participation experts and increase awareness of the importance of public participation in decision-making, as well as on the ability of IT/GIS tools to assist participative processes.

suggested measures have been widely prescribed (Robinson, 2002; UNECE, 1998) the results established an overall context within which a comprehensive set of rules to improve current participation practice could be developed.

\section{Contrasting opinions}

Public participation, a component of most environmental assessment and planning processes worldwide, was emphasized by respondents as having significant limitations. This general perception agrees with published observations indicating that successful participation frequently proves problematic (Morris \& Morris, 2005). Public participation usually occurs too late in the decision-making process and, as a result, public involvement has a limited scope in time and scale (Shepherd \& Bowler, 1997). Furthermore, systems for the inclusion of public concerns and interests in assessment and decision-making have seldom been defined (Gonzalez, Gilmer, Foley, Sweeney, \& Fry, 2005). Survey findings supported the opinion that partnership or delegated public power (i.e. true collaboration) leading to shared-decision-making can rarely be found in practice (Churchman \& Sadan, 2002; Hopkins et al., 2004), and political and/or economic interests tend to overrule public consultation (Palerm, 2005).

The results of this study support the view that a successful public participation programme depends on the method of involvement applied and the timely incorporation of participative procedures in the overall process. Nevertheless, some responses also suggested that the form of public participation alone does not determine success; rather it is factors related to the history of the issue, the context of participation, the expertise of those planning the effort, and the commitment of the regulatory agency (cf. Chess \& Purcell, 1999), which ultimately affect the outcomes. It was also noted that the process itself and the methods involved are part of a wider community capacity building. Moreover, ensuring open communication and transparency through the process enhances empowerment, lends credibility, and promotes involvement, majority support and approval. It was recognised that combining technology with more conventional ways of delivering and gathering information enhanced the transparency and integration of public perceptions within environmental assessment procedures. Practitioners considered that physical presence is important, which supports Risse, Crowley, Vincke, and Waaub (2003) and Therivel, Wilson, Thompson, Heaney, and Pritchard (1992) who indicate that, although more time-consuming and costly than Internet-based participation, with sufficient time and resources round-tables and open hearings generally facilitate greater credibility and are more legitimate for the public. However, it was also acknowledged that IT-aided participation provides an opportunity to promote involvement by reaching a wider public. In addition, participatory processes such as GIS could help visualise and enhance awareness of the spatial implications of a decision problem. The spatial representation of issues could allow a unique communication of viewpoints on a range of issues to different sectors of society, 
and this democratisation of spatial analysis could make some of the choices made in achieving a decision more explicit (Carver, 2001; Cinderby, 1999). Despite the increasing interest in PPGIS (Al-Kodmany, 2002; Goodchild et al., 1999; Haklay \& Tobón, 2003; Kingston et al. 2000), the opinions expressed in this survey contributed to identify data, software and expertise/knowledge as ongoing issues. GIS use could be promoted by adopting measures to increase the availability, accessibility, transparency and usability of spatial data. Similarly, enhancing GIS knowledge through education and the development of user-friendly GIS interfaces (Haklay \& Tobón, 2003) could promote IT-aided public participation methods. GIS-based Internet methods are seen as likely to play more significant role in future participative processes (Weiner et al., 2002).

\section{Conclusion}

Environmental, economic and social aspects of EIA/ SEA related decision-making can be integrated with political will by appropriately informing and involving affected/ concerned stakeholders and the general public. The underlying purpose of public participation in both EIA and SEA is to create understanding and subsequently make the necessary and recognised trade-offs to help achieve a sustainable outcome. In this context, the environmental focus should be substantial to meet the wider public interest and to avoid environmental considerations being overruled by other economic and social goals. IT/GIS-based approaches could assist in such processes by enabling wider public involvement. Moreover, GIS could communicate information more effectively by illustrating both the location of environmental resources/sensitivities and the potential outcomes of possible future scenarios.

The outcome of this research, based on a global survey, suggested that Internet-based GIS could facilitate participative processes and has the potential to significantly contribute to the openness and accountability of decisionmaking. Observed core barriers to wider Internet and GIS use include access to and the complexity of the technology. Social and educational barriers, together with issues in relation to data accessibility and quality also continue to present constraints in terms of effective use. However, the popularisation of the Internet has had an enormous impact on geographic information technologies and has opened the potential for new visions of a geospatially enabled world (Goodchild, 2006). The results of this study indicated that making GIS and appropriate datasets available to the public over the Internet may provide an opportunity to improve accessibility to spatial information and promote equal rights for stakeholders to view and evaluate the information being considered by decision-makers. In addition, it was identified that participatory GIS could equally improve spatial awareness, which in turn could support and enhance both participation and decision-making processes in environmental planning, especially when combined with more traditional ways of gathering and presenting data. Given the political will and a clearer definition of public participation procedures, such enhanced community and stakeholder involvement could make a significant contribution to the process and cease to be simply a bureaucratic requirement. Taking into consideration the technological challenges discussed in this paper, IT/GISmediated participative decision-making has the potential to implicate wider public, improve data communication, gathering and analysis, and lead to more comprehensible and egalitarian outcomes.

\section{References}

Abelson, J., Forest, P. G., Smith, P., Martin, E., \& Gauvin, F. P. (2001). A review of public participation and consultation. URL: http:// www.vcn.bc.ca/citizens-handbook/compareparticipation.pdf.

Al-Kodmany, K. (2002). GIS and the artist: Shaping the image of a neighbourhood in participatory environmental design. In D. Weiner, T. M. Harris, \& W. J. Craig (Eds.), Community participation and geographic information systems (pp. 320-329). London: Taylor and Francis.

Allen, P. (1998). Public participation in resolving environmental disputes and the problem of representativeness. Risk: Health, Safety and Environment, 9, 297-308.

Arnstein, S. R. (1969). A ladder of citizen participation. Journal of American Planning Association, 35(4), 216-224.

Bauer, J. M., Berne, M., \& Maitland, C. F. (2002). Internet access in the European union and in the United States. Telematics and Informatics, 19(2), 117-137.

Bishop, A. B. (1973). Public participation in water resources planning Institute for water resources (IWR), Report 70-7.

Bishop, A. B. (1998). Communication in the planning process. In J. L. Creighton, J. Delli Priscoli, \& M. Dunning (Eds.), Public involvement techniques: A reader of ten years experience at the institute for water resources. IWR Report 82-R1.

Bojórquez-Tapia, L., Diaz-Mondragón, S., \& Ezcurra, E. (2001). GISbased approach for participatory decision making and land suitability assessment. International Journal of Geographical Information Science, 15(2), 129-151.

Brooks, S., Donovan, P., \& Rumble, C. (2005). Developing nations, the digital divide and research databases. Serials Review, 31(4), 270 278.

Carver, S. (2001). Participation and geographical information: A position paper. In ESF-NSF workshop on access to geographic information and participatory approaches using geographic information, Spoleto, 6-8 December 2001. Conference paper.

Carver, S. (2003). The future of participatory approaches using geographic information: Developing a research agenda for the 21st century. Urban and Information Systems Association Journal, 15(APA I), 61-71.

CEAA (1999). Cabinet directive on the environmental assessment of policy, plan and program proposals. Ottawa, Canada: Canadian Environmental Assessment Agency; Minister of Supply and Services Canada.

CEAA (2004). Amended 1999 cabinet directive on the environmental assessment of policy, plan and program proposals. Ottawa, Canada: Canadian Environmental Assessment Agency, Minister of Supply and Services Canada.

CEC (1985). Directive 1985/337/EEC on the assessment of the effects of certain public and private projects on the environment, 27 June 1985. Council of the European commission. Official Journal of the European Union L0337 (p. L 175) [5.7.1985].

CEC (1997). Directive 1997/11/EC amending directive $85 / 337 /$ EEC on the assessment of the effects of certain public and private projects on the environment, 3 March 1997. Council of the European commission. Official Journal of the European Union L0011, 3. 
CEC (2001). Directive 2001/42/EC on the assessment of the effects of certain plans and programmes on the environment, 27 June 2001. Council of the European commission. Official Journal of the European Union L 197/30 [21.7.2001].

CEC (2003). Directive 2003/35/EC providing for public participation in respect of the drawing up of certain plans and programmes relating to the environment and amending with regard to public participation and access to justice council directives 85/337/EEC and 96/61/EC. Council of the European commission. Official Journal of the European Union L 156 [25.6.2003].

CEC (2007). Directive 2007/2/EC establishing an infrastructure for spatial information in the European community (INSPIRE), 14 March 2007. European parliament and European council. Official Journal of the European Union, L108/1 [24.5.2007].

Charlton, C., Gittings, C., Leng, P., Little, J., \& Neilson, I. (1999). Bringing the internet to the community. Interacting with Computers, 12(1), 51-61.

Chess, C., \& Purcell, K. (1999). Public participation and the environment: Do we know what works? Environmental Science and Technology, 33(16), 2685-2692.

Churchman, A., \& Sadan, E. (2002). Rethinking public participation. In IAPS conference, La Coruña, Spain, July 2002. Conference paper.

Cinderby, S. (1999). Participatory geographic information systems: The future of environmental GIS? International Journal of Environment and Pollution, 11(3), 304-315.

Connor, D. (1999). Public participation and civil society. Constructive Citizen Participation, 27(3), 6-10.

Craglia, M., \& Masser, I. (2003). Access to geographic information: A European perspective. Urban and Information Systems Association Journal, 15(APA I), 51-59.

Craglia, M., \& Onsrud, H. (2003). Report of meeting and research agenda; a workshop funded jointly by the European science foundation and the national science foundation. Urban and Information Systems Association Journal, 15(APAII), 9-15.

Creighton, J. L. (1992). Involving citizens in community decision making. Washington DC programme for community problem solving. Washington, USA: National League of Cities.

Creighton, J. L. (2005). The public participation handbook: Making better decisions through citizen involvement. NY, USA: Jossey Bass.

Curwell, S., Deakin, M., Cooper, I., Paskaleva-Shapira, K., Ravetz, J., \& Babicki, D. (2005). Citizen's expectations of information cities: Implications for urban planning and design. Building Research and Information, 33(1), 55-66.

de Man, E. (2003). Cultural and institutional conditions for using geographic information; access and participation. Urban and Information Systems Association Journal, 15(APA I), 29-33.

de Montalvo, U. M. (2003). In search of rigorous models for policyoriented research: A behavioural approach to spatial data sharing. Urban and Information Systems Association Journal, 15(APA I), 19-28.

Doyle, S., Dodge, M., \& Smith, A. (1998). The potential of web-based mapping and virtual reality technologies for modelling urban environments. Computers, Environment and Urban Systems, 22(2), 137-155.

Elwood, S., \& Leitner, H. (1998). GIS and community-based planning: Exploring the diversity of neighbourhood perspectives and needs. Cartography and Geographic Information Systems, 25(2), 77-88.

EPD (1997). Environmental impact assessment ordinance L.N. 362 of 1997. Environmental Protection Department of Hong Kong.

Furlong, S. R. (2005). Interest group participation in rule making: A decade of change. Journal of Public Administration Research and Theory, 15(3), 353-370.

Gonzalez, A., Gilmer, A., Foley, R., Sweeney, J., \& Fry, J. (2005). Dynamics of a decision support system in strategic environmental assessment implementation. In IAIÁ05 ethics and quality, annual conference of international association for impact assessment, Boston 31 May-3 June 2005. Conference paper.

Goodchild, M. (2006) The spatial web: visions for a geospatial world. National Centre for Geocomputation, Maynooth, Ireland, 12 April 2006. Lecture paper.
Goodchild, M., Egenhofer, M., Kemp, K., Mark, D., \& Sheppard, E. (1999). Introduction to the Varenius project. International Journal of Geographical Information Science, 13(8), 731-745.

Haklay, M., \& Tobón, C. (2003). Usability evaluation and PPGIS: Towards a user-centred design approach. International Journal of Geographical Information Science, 17(6), 577-592.

Helge, F. (2005). Past and future of public participation in Norwegian physical planning. European Planning Studies, 13(1), 157-174.

Hopkins, L. D., Twidale, M., \& Pallathucheril, V. G. (2004). Interface devices and public participation. In Public participation GIS conference madison, Wisconsin, July 2004. URL: http://www.isrl.uiuc.edu/ $\sim$ twidale/pubs/publicparticipation.pdf. Conference paper.

Howard, D. (1998). Geographic information technologies and community planning: Spatial empowerment and public participation. Project varenius specialist meeting, Santa Barbara, CA. URL: http:// www.ncgia.ucsb.edu/varenius/ppgis/papers/index.html. Conference paper.

Jankowski, P., \& Nyerges, T. (2003). Toward a framework for research on geographic information-supported participatory decision-making. Urban and Information Systems Association Journal, 15(APAI), 9-17.

Jordan, G., \& Shrestha, B. (2000). A participatory GIS for community forestry user groups in Nepal: Putting people before the technology. Participatory learning and action notes 39. International Institute for Environment and Development.

Kangas, J., \& Store, R. (2003). Internet and teledemocracy in participatory planning of natural resources management. Landscape and Urban Planning, 62(2), 89-101.

Kavanaugha, A., Carrollb, J. M., Rossonb, M. B., Reesec, D. D., \& Zina, T. T. (2005). Participating in civil society: The case of networked communities. Interacting with Computers, 17(1), 9-33.

Kingston, R. (1998). Web-based GIS for public participation decision making in the UK. Empowerment, marginalisation and public participation GIS, Santa Barbara, California, October 14-17, 1998. URL http://www.ncgia.ucsb.edu/varenius/ppgis/papers/kingston/kingston. html. Conference paper.

Kingston, R., Carver, S., Evans, A., \& Turton, I. (2000). Web-based public participation geographical information systems: An aid to local environmental decision-making. Computers, Environment and Urban Systems, 24(2), 109-125.

Kyem, P. A. K. (2002). Examining the community empowerment agenda in public participation GIS applications. In Public participation GIS (PPGIS) conference, New Brunswick, NJ, USA, July 21-23, 2002. URL: http://www.iapad.org/publications/ppgis/community_ empowerment_in_PPGIS.pdf.

Liebow, E. (1993). Who is expert at representing environmental hazards? A commentary on the disabling effects of an expert/layperson dichotomy. The Environmental Professional, 15, 288-292.

Loveridge, D., \& Street, P. (2005). Inclusive foresight. Journal of Future Studies, Strategic Thinking and Policy, 7(3), 31-47.

Merrick, M. (2003). Reflections on PPGIS: A view from the trenches. Urban and Information Systems Association Journal, 15(APA II), 33-39.

Morris, C. T., \& Morris, R. M. (2005). The Ythan project: A case study on improving catchment management through community involvement. Journal of Environmental Planning and Management, 48(3), 413-429.

NEPA (1969). National environmental protection act. Senate and house of representatives of the United States of America. URL: http:// www.fhwa.dot.gov/environment/nepatxt.htm.

Niles, S., \& Hanson, S. (2003). A new era of accessibility? Urban and Information Systems Association Journal, 15(APA I), 35-41.

Oden, M. D., \& Lentz, R. G. (2001). Digital divide or digital opportunity in the Mississippi delta region of the US. Telecommunications Policy, 25(5), 291-313.

Onsrud, H. J. (1999). Liability in the use of GIS and geographical datasets. In P. A. Longley, M. F. Goodchild, D. J. Maguire, \& D. W. Rhind (Eds.), Geographical information systems 2: Managing issues and applications. NY: John Wiley and Sons, Inc. 
Palerm, J. (2005). Needs and opportunities for SEA in Mexico: A view through the Arcediano dam case study. Impact Assessment and Project Appraisal, 23(2), 125-134.

Peterson, M. N., Peterson, M. J., \& Tarla, R. (2005). Conservation and the myth of consensus. Conservation Biology, 19(3), 762 767.

Portney, K. E. (1991). Public environmental policy decision-making: Citizen roles. In Environmental decision making: A multidisciplinary perspective. NY: Van Nostrand Reinhold.

Pring, G., Zillman, D., \& Lucas, A. (2003). The law of public participation in global energy and resources development. Journal of Energy and Natural Resources Law, 1(2), 14-17.

Risse, N., Crowley, M., Vincke, P., \& Waaub, J. P. (2003). Implementing the European SEA directive: The member states' margin of discretion. Environmental Impact Assessment Review, 23, 453-470.

Robinson, L. (2002). The qualities of effective public participation processes. URL: http://media.socialchange.net.au/people/les/ Effective participation.pdf.

Roche, S. (2003). Geographic information and public participation: Research proposal from a French perspective. Urban and Information Systems Association Journal, 15(APA II), 41-48.

Rugg, R. D. (2003). A framework for the use of geographic information in participatory community planning and development. Urban and Information Systems Association Journal, 15(APA II), 7580.

Schroeder, P. (1997). GIS in public participation settings. Maine: University Consortium for Geographic Information Science (UCGIS), June 15-21, 1997. Conference paper.

Scott, D., \& Oelofse, C. (2005). Social and environmental justice in South African cities: Including invisible stakeholders in environmental assessment procedures. Journal of Environmental Planning and Management, 48(3), 445-467.

Shepherd, A., \& Bowler, C. (1997). Beyond the requirements: Improving public participation in EIA. Journal of Environmental Planning and Management, 40(6), 725-738.

Shiffer, M. (1995). Interactive multimedia planning support: Moving from stand alone systems to the web. Environment and Planning B: Planning and Design, 22, 649-664.
Siebenhüner, B., \& Barth, V. (2004). The role of computer modelling in participatory integrated assessment. Environmental Impact Assessment Review, 25, 367-389.

Simpson, L., Daws, L., \& Pini, B. (2004). Public internet access revisited. Telecommunications Policy, 28(3-4), 323-337.

Speller, G., \& Ravenscroft, N. (2005). Facilitating and evaluating public participation in urban parks management. Local Environment, 10(1), 41-56.

Stolp, A., Groen, W., Van Vliet, J., \& Vanclay, F. (2004). Citizen values assessment: Incorporating citizens' value judgements in environmental impact assessment. Impact Assessment and Project Appraisal, 20(1), $11-23$.

Susskind, L. (1999). An alternative to Robert's rules of order for groups, organizations, and adhoc assemblies that want to operate by consensus. In L. Susskind, S. McKearnan, \& J. Thomas-Larmer (Eds.), The consensus building handbook. Thousand Oaks, California, US: Sage Publications.

Susskind, L., \& Cruikshank, J. (1987). Breaking the impasse: Consensual approaches to resolving public disputes. NY: Basic Books.

Therivel, R., Wilson, E., Thompson, S., Heaney, D., \& Pritchard, D. (1992). Strategic environmental assessment. London: Earthscan Publications Ltd.

Towers, G. (1997). GIS versus the community. Applied Geography, 17(22), $111-125$.

UNECE (1998). Convention on access to information, public participation in decision making and access to justice in environmental matters. URL: http://www.unece.org/env/pp/documents/cep43e.pdf.

Weiner, D., \& Harris, T. M. (2003). Community-integrated GIS for land reform in South Africa. Urban and Information Systems Association Journal, 15(APA II), 61-73.

Weiner, D., Harris, T. M., \& Craig, W. J. (2002). Community participation and geographic information systems. London: Taylor and Francis.

Wood, J. (2005). 'How green is my valley? Desktop geographic information systems as a community-based participatory mapping tool. Area, $37(2), 159-170$.

Yang, K. (2005). Public administratorś trust in citizens: A missing link in citizen involvement efforts. Public Administration Review, 65(3), 273-285. 